Supporting Information for:

\title{
Effect of Polymerized Ionic Liquid Structure and Morphology on Shockwave Energy Dissipation
}

\author{
Jaejun Lee ${ }^{1,3}$, Vivian Lau ${ }^{2,3}$, Yi Ren ${ }^{2,3}$, Christopher M. Evans ${ }^{1}$, Jeffrey S. Moore ${ }^{1,2,3}$, \\ and Nancy R. Sottos*,1,3 \\ ${ }^{1}$ Department of Materials Science and Engineering, ${ }^{2}$ Department of Chemistry, ${ }^{3}$ Beckman Institute for \\ Advanced Science and Technology, University of Illinois at Urbana-Champaign, Urbana, IL 61801
}

\section{General methods}

All reactions were carried out in flame-dried glassware, under an atmosphere of dry $\mathrm{N}_{2}$ or Argon unless otherwise indicated. Organic reagents were purchased from Sigma-Aldrich and used as received. LiNTf $f_{2}$ was purchased from Oakwood Chemical and stored in a desiccator over $\mathrm{CaSO}_{4}$. THF and DMF were dried by passing through an activated alumina column on a Pure Process Technology solvent purification system; methanol and water were HPLC grade and used as received. Flash chromatography was performed with 230-400 mesh silica gel from Silicycle. NMR spectra were recorded on Varian Unity Inova 500 spectrometers, and referenced relative to residual solvent. High-resolution mass spectra were obtained by electron impact ionization on a Waters 70-VSE spectrometer. Gel permeation chromatography was carried out at $50{ }^{\circ} \mathrm{C}$, eluting with DMF (containing $0.1 \mathrm{M} \mathrm{LiBr}$ ) at $1.0 \mathrm{~mL} / \mathrm{min}$, on a Waters system equipped with a Waters 1515 isocratic pump, 2414 refractive index detector, 2998 photodiode array detector, and a miniDAWN TREOS 3-angle laser light scattering detector from Wyatt Technology.

\section{Synthesis}

\section{General procedure for synthesis of polymerized ionic liquids (PIL-C6 - C16)}

To a flame-dried round-bottom flask with a magnetic stir bar was added $5 \mathrm{mmol}$ each of $\alpha, \omega$-dibromoalkane and $\alpha, \omega$-bis(imidazoyl)alkane. The mixture was dissolved in DMF $(12 \mathrm{~mL})$, and stirred at $80{ }^{\circ} \mathrm{C}$ for $48 \mathrm{~h}$. After cooling to $23{ }^{\circ} \mathrm{C}$, the solvent was removed by short-path vacuum distillation. The resulting bromidecontaining polymerized ionic liquid was dissolved in a minimum of DMF and precipitated into water at 23 ${ }^{\circ} \mathrm{C} 2$ times. Following precipitation, the solid polymer was dissolved in methanol with $25 \mathrm{mmol}_{\text {of }} \mathrm{LiNTf}_{2}$ and stirred at $23{ }^{\circ} \mathrm{C}$ for $24 \mathrm{~h}$ in order to achieve ion exchange. Methanol was removed by distillation at reduced pressure, and then the ion exchanged PIL was precipitated into water 3 times. For PIL-C6 and PIL$\mathrm{C} 8$, dialysis $(\mathrm{MWCO}=3.5 \mathrm{kDa}$ ) was carried out in 1:1 $\mathrm{MeOH} / \mathrm{Water}$ to exclude low molecular weight products. The PILs were lyophilized prior to characterization. Complete exchange of bromide for $\mathrm{NTf}_{2}{ }^{-}$ was confirmed by silver nitrate test, indicating the absence of bromide.

\section{PIL-C6}

Synthesized from 1,6-dibromohexane and 1,6-bis(imidazoyl)hexane as a light pink thick syrup that solidifies on standing in $38 \%$ yield following dialysis. ${ }^{1} \mathrm{H}$ NMR $\left(500 \mathrm{MHz}, \mathrm{DMSO}-\mathrm{d}_{6}\right): \delta 9.13(\mathrm{~s}, 1 \mathrm{H}$ per repeating unit); $7.77(\mathrm{~s}, 2 \mathrm{H}) ; 4.13(\mathrm{t}, J=8.0 \mathrm{~Hz}, 4 \mathrm{H}) ; 1.82-1.73(\mathrm{~m}, 4 \mathrm{H}) ; 1.31-1.22(\mathrm{~m}, 4 \mathrm{H}) . \mathrm{Mn}=15.8$ $\mathrm{kg} / \mathrm{mol} ;$ PDI $=1.21$.

\section{PIL-C8}


Synthesized from 1,8-dibromooctane and 1,8-bis(imidazoyl)octane as a thick pink syrup in 48\% yield following dialysis. ${ }^{1} \mathrm{H}$ NMR (DMSO- $\mathrm{d}_{6}$ ): $\delta 9.14$ (s, $1 \mathrm{H}$ per repeating unit); $7.76(\mathrm{~s}, 2 \mathrm{H}), 4.13(\mathrm{t}, J=7.3 \mathrm{~Hz}$, $4 \mathrm{H}$ ); 1.77 (quint, $J=7.0 \mathrm{~Hz}, 4 \mathrm{H}) ; 1.32-1.16$ (m, $8 \mathrm{H}) . \mathrm{Mn}=16.7 \mathrm{~kg} / \mathrm{mol} ; \mathrm{PDI}=1.23$.

\section{PIL-C12}

Synthesized from 1,12-dibromododecane and 1,12-bis(imidazoyl)dodecane as a thick amber syrup in 79\% yield. ${ }^{1} \mathrm{H}$ NMR (500 MHz, DMSO-d ${ }_{6}$ ): $\delta 9.15$ (s, $1 \mathrm{H}$ per repeating unit); $7.77(\mathrm{~s}, 2 \mathrm{H}) ; 4.13$ (t, $J=7.0 \mathrm{~Hz}$, $4 \mathrm{H}$ ); 1.76 (quint, $J=7.0 \mathrm{~Hz}, 4 \mathrm{H}) ; 1.30-1.14(\mathrm{~m}, 16 \mathrm{H}) . \mathrm{Mn}=17.3 \mathrm{~kg} / \mathrm{mol} ; \mathrm{PDI}=1.53$.

\section{PIL-16}

Synthesized from 1,16-dibromohexadecane and 1,16-bis(imidazoyl)hexadecane as a thick amber syrup in $88 \%$ yield. ${ }^{1} \mathrm{H}$ NMR $\left(500 \mathrm{MHz}, \mathrm{DMSO}-\mathrm{d}_{6}\right): \delta 9.15$ (s, $1 \mathrm{H}$ per repeating unit); $7.76(\mathrm{~s}, 2 \mathrm{H}) ; 4.13(\mathrm{t}, J=7.0$ $\mathrm{Hz}, 4 \mathrm{H}$ ); 1.76 (quint, $J=7.3 \mathrm{~Hz}, 4 \mathrm{H}) ; 1.28-1.14$ (m, 24H). $\mathrm{Mn}=15.9 \mathrm{~kg} / \mathrm{mol}$; PDI = 1.53 .

\section{General procedure for synthesis of $\alpha, \omega$-bis(imidazoyl)alkanes}

Sodium hydride (60\% dispersion in mineral oil; $1.75 \mathrm{~g}, 43.6 \mathrm{mmol}, 2.4$ equiv.) was added portion-wise to a suspension of imidazole ( $2.72 \mathrm{~g}, 40 \mathrm{mmol}, 2.2$ equiv.) and potassium iodide ( $302 \mathrm{mg}, 1.8 \mathrm{mmol}, 10 \mathrm{~mol} \%$ ) in $100 \mathrm{~mL}$ of THF at $0{ }^{\circ} \mathrm{C}$. After stirring for 2 hours at $23^{\circ} \mathrm{C}$, the reaction was cooled to $0{ }^{\circ} \mathrm{C}$ and a solution of $\alpha, \omega$-dibromoalkane $(18.2 \mathrm{mmol})$ in THF was added dropwise. The reaction was heated to $60^{\circ} \mathrm{C}$ overnight, then cooled to $23{ }^{\circ} \mathrm{C}$ and filtered through a short plug of Celite and rinsed with ethyl acetate. The desired

product was obtained after purification of the crude material by column chromatography on $\mathrm{SiO}_{2}$, eluting with $100 \% \mathrm{CH}_{2} \mathrm{Cl}_{2}$.

\section{1,6-bis(imidazoyl)hexane}

Synthesized from 1,6-dibromohexane to give a thick, pale-yellow oil in 62\% yield. ${ }^{1} \mathrm{H}$ NMR (500 MHz, $\left.\mathrm{CDCl}_{3}\right): \delta 7.42(\mathrm{~s}, 2 \mathrm{H}) ; 7.03(\mathrm{~s}, 2 \mathrm{H}) ; 6.86(\mathrm{~s}, 2 \mathrm{H}) ; 3.89(\mathrm{t}, J=7.0 \mathrm{~Hz}, 4 \mathrm{H}) ; 1.77-1.70(\mathrm{~m}, 4 \mathrm{H}) ; 1.28-1.26$ (m, 4H). ${ }^{13} \mathrm{C}$ NMR $\left(125 \mathrm{MHz}, \mathrm{CDCl}_{3}\right): \delta 137.1,129.5,118.7,46.8,30.9,26.1$. HRMS-ESI (m/z): [M + $\left.\mathrm{H}^{+}\right]$ calculated for $\mathrm{C}_{12} \mathrm{H}_{19} \mathrm{~N}_{4}, 219.1604$; found 219.1614.

\section{1,8-bis(imidazoyl)octane}

Synthesized from 1,8-dibromooctane to give an off-white solid in $66 \%$ yield. ${ }^{1} \mathrm{H} \mathrm{NMR}\left(500 \mathrm{MHz}, \mathrm{CDCl}_{3}\right)$ : $\delta 7.46(\mathrm{~s}, 2 \mathrm{H}) ; 7.04(\mathrm{~s}, 2 \mathrm{H}) ; 6.88(\mathrm{~s}, 2 \mathrm{H}) ; 3.90(\mathrm{t}, J=7.1 \mathrm{~Hz}, 4 \mathrm{H}) ; 1.77-1.71(\mathrm{~m}, 4 \mathrm{H}) ; 1.31-1.20(\mathrm{~m}, 8 \mathrm{H})$. ${ }^{13} \mathrm{C} \mathrm{NMR}\left(125 \mathrm{MHz}, \mathrm{CDCl}_{3}\right): \delta 137.1,129.4,118.8,47.0,31.0,28.9,26.4$. HRMS-EI (m/z): [ $\left.\mathrm{M}^{+}\right]$calculated for $\mathrm{C}_{14} \mathrm{H}_{22} \mathrm{~N}_{4}, 246.1844$; found 246.1845 .

\section{1,12-bis(imidazoyl)dodecane}

Synthesized from 1,12-dibromododecane to give a white solid in $57 \%$ yield. ${ }^{1} \mathrm{H}$ NMR $\left(500 \mathrm{MHz}, \mathrm{CDCl}_{3}\right)$ : $\delta 7.45(\mathrm{~s}, 2 \mathrm{H}) ; 7.04(\mathrm{~s}, 2 \mathrm{H}) ; 6.89(\mathrm{~s}, 2 \mathrm{H}) ; 3.91(\mathrm{t}, J=7.1 \mathrm{~Hz}, 4 \mathrm{H}) ; 1.77-1.74(\mathrm{~m}, 4 \mathrm{H}) ; 1.27-1.23(\mathrm{~m}, 16 \mathrm{H})$. ${ }^{13} \mathrm{C} \mathrm{NMR}\left(125 \mathrm{MHz}, \mathrm{CDCl}_{3}\right): \delta 137.1,129.4,118.8,47.1,31.1,29.5,29.4,29.1,26.6$. HRMS-ESI (m/z): $\left[\mathrm{M}+\mathrm{H}^{+}\right]$calculated for $\mathrm{C}_{18} \mathrm{H}_{31} \mathrm{~N}_{4}, 303.2543$; found 219.2542 . 


\section{1,16-bis(imidazoyl)hexadecane}

Synthesized from 1,16-dibromohexadecane to give a white solid in $88 \%$ yield. ${ }^{1} \mathrm{H}$ NMR $\left(500 \mathrm{MHz}, \mathrm{CDCl}_{3}\right)$ : $\delta 7.46(\mathrm{~s}, 2 \mathrm{H}) ; 7.05(\mathrm{~s}, 2 \mathrm{H}) ; 6.90(\mathrm{~s}, 2 \mathrm{H}) ; 3.92(\mathrm{t}, J=7.2 \mathrm{~Hz}, 4 \mathrm{H}) ; 1.79-1.75(\mathrm{~m}, 4 \mathrm{H}) ; 1.29-1.24(\mathrm{~m}, 24 \mathrm{H})$. ${ }^{13} \mathrm{C}$ NMR $\left(125 \mathrm{MHz}, \mathrm{CDCl}_{3}\right): \delta$ 137.1, 129.4, 118.8, 47.1, 31.1, 29.69, 29.66, 29.58, 29.5, 29.1, 26.6. HRMS-ESI (m/z): $\left[\mathrm{M}+\mathrm{H}^{+}\right]$calculated for $\mathrm{C}_{22} \mathrm{H}_{39} \mathrm{~N}_{4}, 359.3169$; found 359.3179 .

\section{1,16-dibromohexadecane}

A flame-dried round bottom flask was charged with 1,16-dihydroxyhexadecane ${ }^{[1]}$ (4.92 $\left.\mathrm{g}, 19.0 \mathrm{mmol}\right)$ and $\mathrm{CBr}_{4}\left(16.4 \mathrm{~g}, 49.5 \mathrm{mmol}, 2.6\right.$ equiv.). The solids were dissolved in $200 \mathrm{~mL}$ of dry $\mathrm{CH}_{2} \mathrm{Cl}_{2}$, then cooled to 0 ${ }^{\circ} \mathrm{C}$. Under flow of $\mathrm{N}_{2}, \mathrm{PPh}_{3}(13.73 \mathrm{~g}, 52.3 \mathrm{mmol}, 2.75$ equiv.) was carefully added. The reaction was stirred to $23{ }^{\circ} \mathrm{C}$ overnight, and then quenched by the addition of methanol $(45 \mathrm{~mL})$. Following rotary evaporation, the crude residue was dissolved in hexanes and washed with methanol 3 times to remove triphenylphosphine oxide. The hexanes phase was then eluted through a short plug of $\mathrm{SiO}_{2}$ and then evaporated to dryness. The product was recrystallized from cold methanol to give $6.57 \mathrm{~g}(17.1 \mathrm{mmol})$ of the desired compound as a white powder in $90 \%$ yield. ${ }^{1} \mathrm{H}$ NMR $\left(500 \mathrm{MHz}, \mathrm{CDCl}_{3}\right): \delta 3.41(\mathrm{t}, J=6.9 \mathrm{~Hz}$, $4 \mathrm{H}) ; 1.85$ (quint, $J=7.1 \mathrm{~Hz}, 4 \mathrm{H}) ; 1.45-1.39(\mathrm{~m}, 4 \mathrm{H}), 1.31-1.26(\mathrm{~m}, 20 \mathrm{H}) .{ }^{13} \mathrm{C} \mathrm{NMR}\left(125 \mathrm{MHz}, \mathrm{CDCl}_{3}\right): \delta$ $34.2,32.9,29.72,29.70,29.6,29.5,28.9,28.3$.

\section{NMR spectra}

\section{PIL-C6}
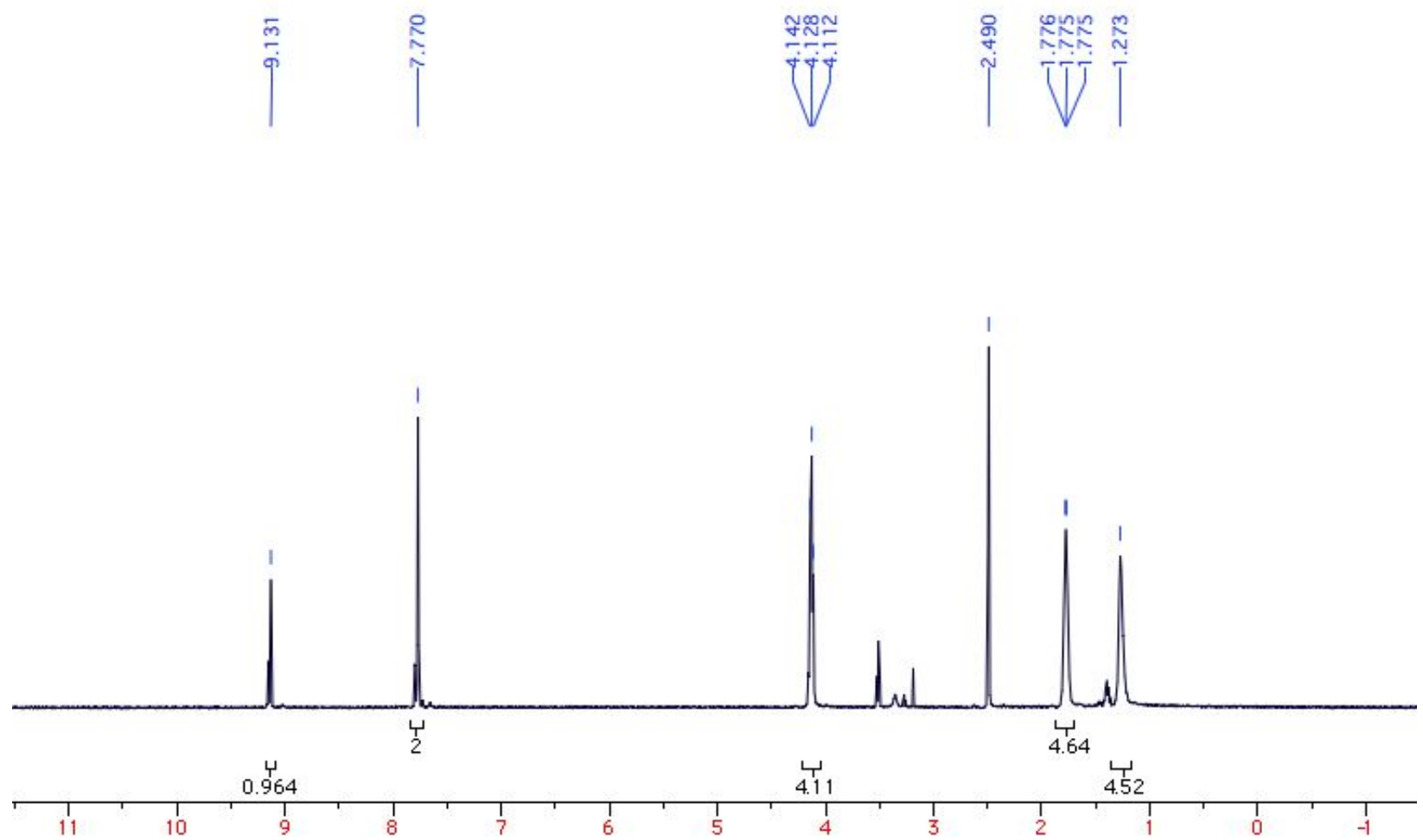

PIL-C8 


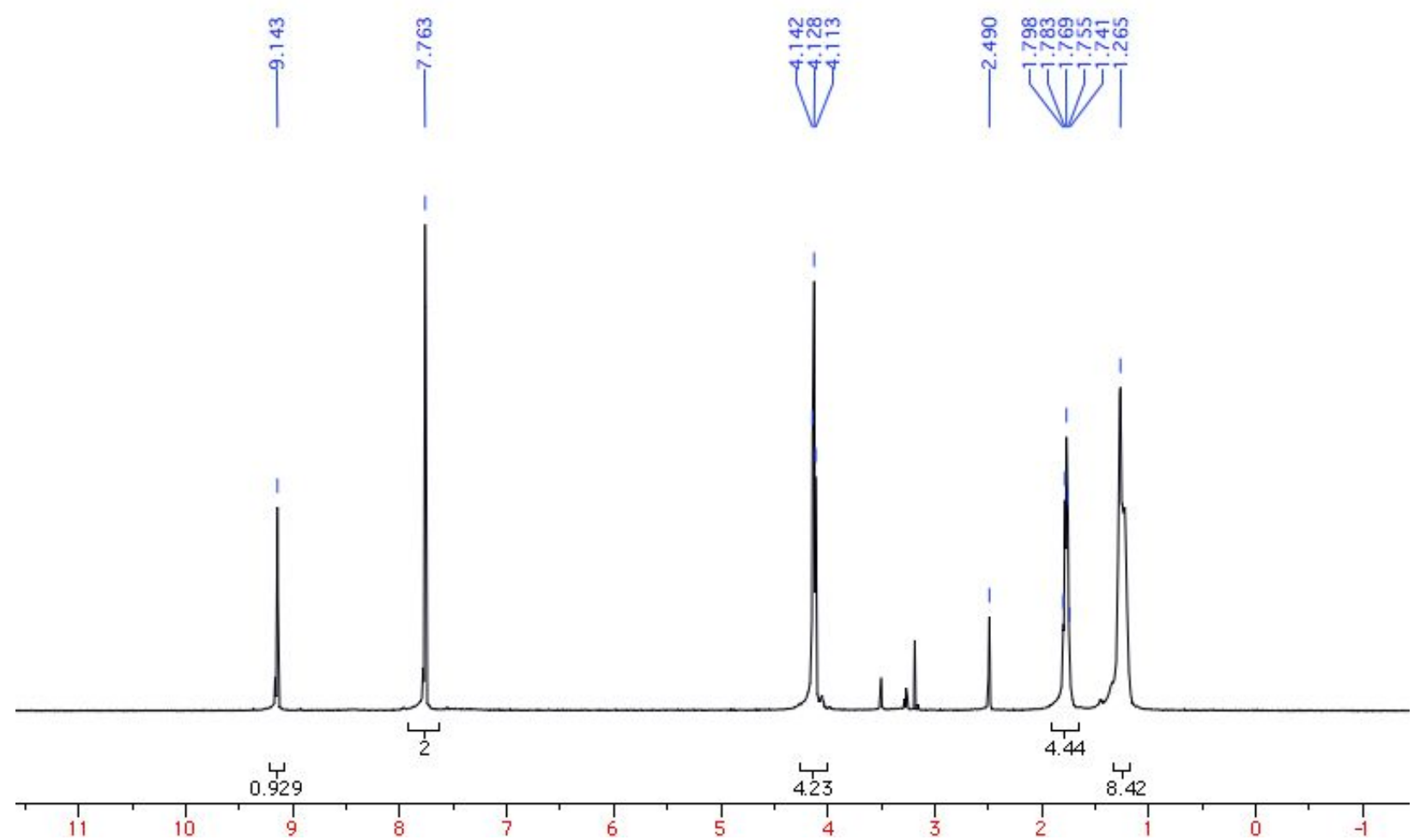

PIL-C12
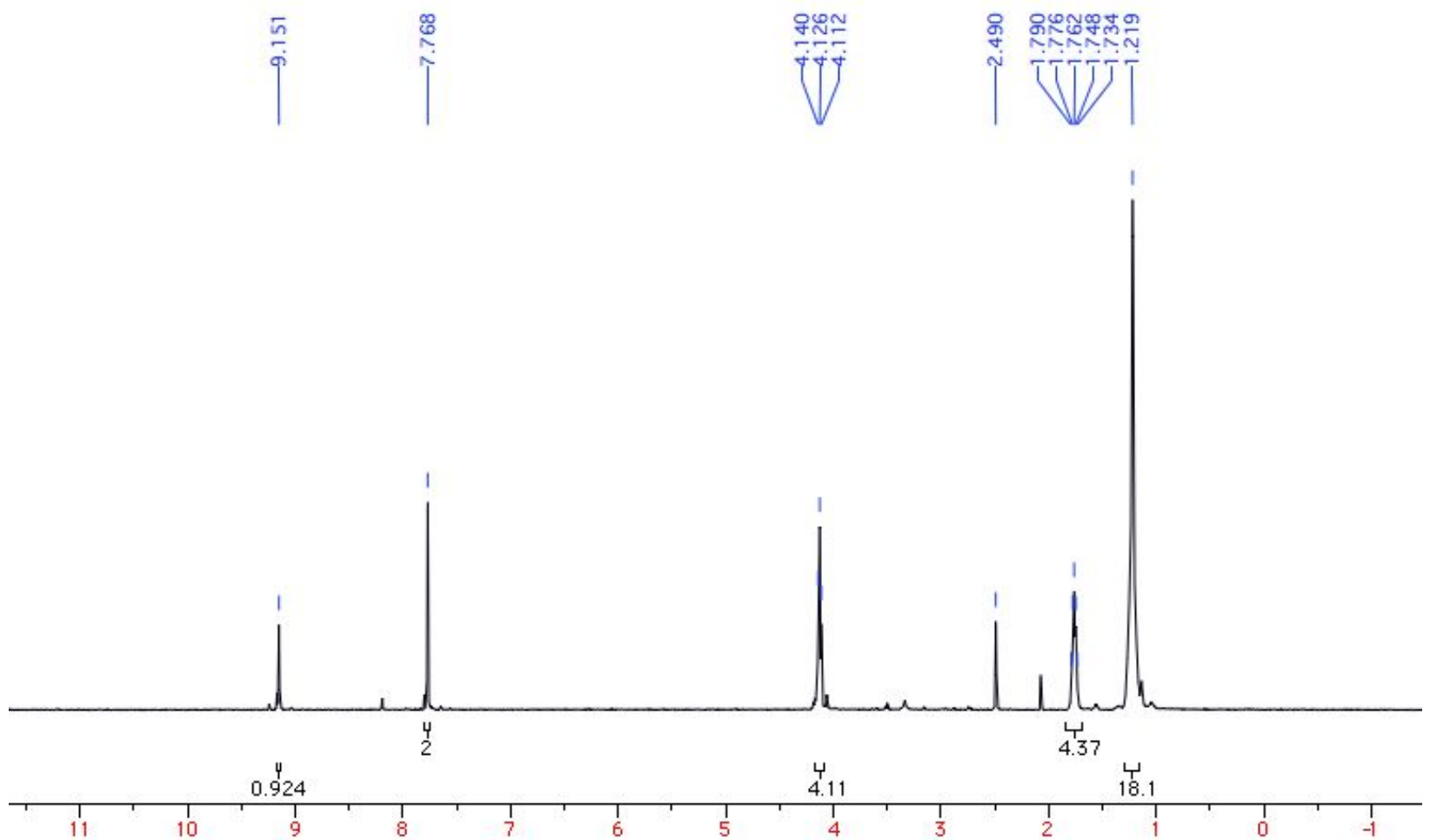

PIL-C16 


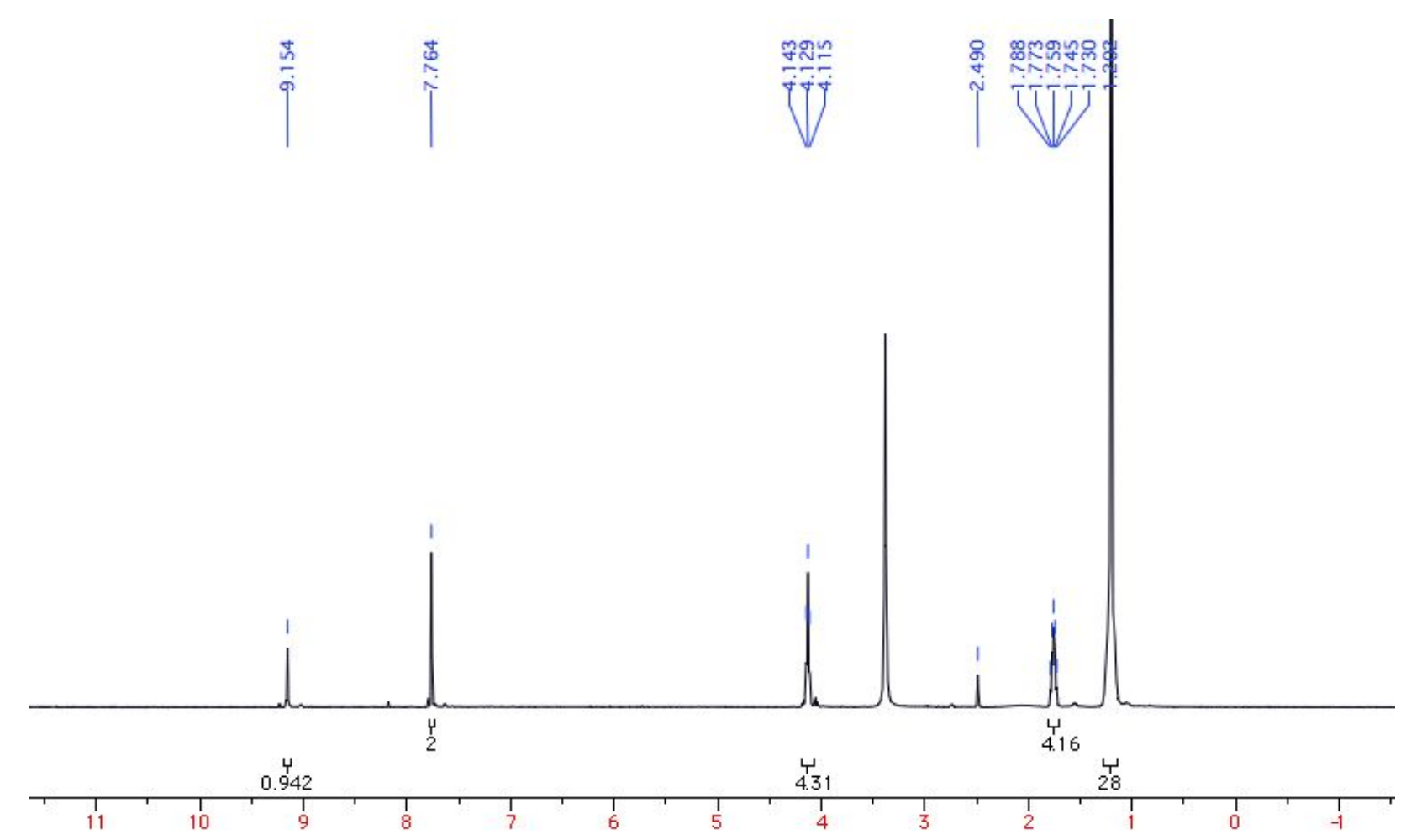

\section{X-ray scattering.}

For crystalline samples, X-ray scattering experiments were conducted using a Rigaku Miniflex 600 X-ray diffractometer with $\mathrm{Cu} \mathrm{K} \alpha$ radiation. A $50 \mu \mathrm{m}$ thick layer of crystalline sample was prepared by dropcasting $25 \mathrm{mg}$ freshly melted PIL on the quartz substrate at $23{ }^{\circ} \mathrm{C}$ which slowly crystallized. Amorphous PIL-C6 samples were prepared by heating the polymer above its melting temperature before filling into a capillary tube. Other amorphous PIL samples were prepared in a capillary tube for wide-angle X-ray scattering. Wide-angle X-ray measurements were performed on a benchtop X-ray scattering setup in the MRL at UIUC using an $8 \mathrm{keV}$ Xenocs GeniX3D Cu Ka ultralow divergence X-ray source and PerkinElmer XRPad 4343F detectors.

\section{Differential scanning calorimeter (DSC) measurements.}

A TA Instrument Q20 Differential Scanning Calorimeter equipped with a Liquid Nitrogen Cooling System (LNCS) was used to measure glass transition temperatures of the PILs. Tzero aluminum pans and lids were used as sample testing containers.

Two cycles were run for each DSC measurement. Each cycle consists of a single heating and cooling process, with a temperature range -100 to $100^{\circ} \mathrm{C}$, and heating/cooling rate of $10^{\circ} \mathrm{C} / \mathrm{min}$. The inflection point of the step from the second heating scan was used to determine the glass transition temperatures. Freshly melted PIL-C6 was placed in the desiccator at $23{ }^{\circ} \mathrm{C}$ over 24 hours before running DSC measurements to determine the melting of PIL-C6. 


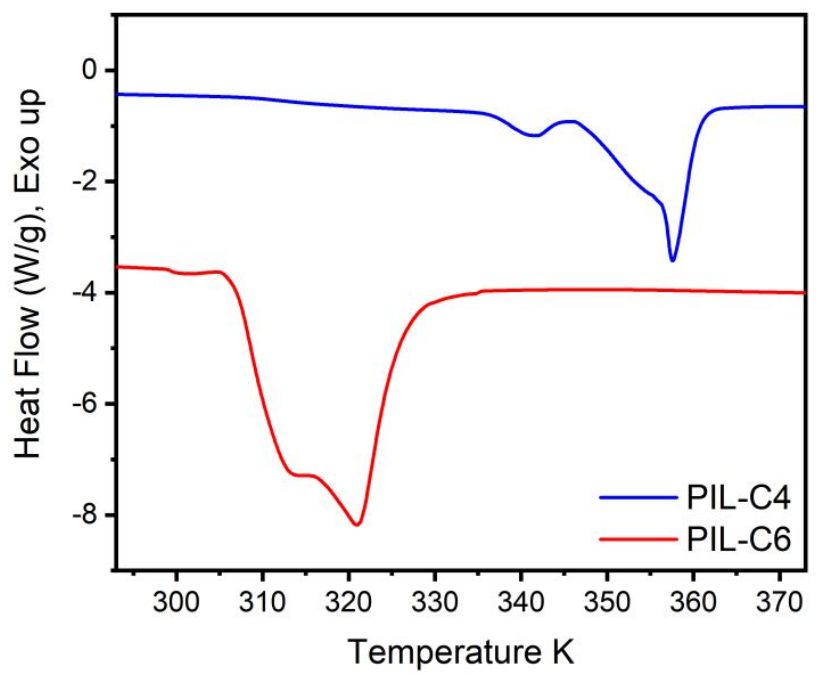

Figure S1. DSC experiments for the PIL-C4 and PIL-C6 crystallized in the first heating cycle. Both were run at $10{ }^{\circ} \mathrm{C} / \mathrm{min}$ rate. Endothermic peaks indicate the melting of crystalline phase. The melting temperature of PIL-C4 (peak maximum $=358 \mathrm{~K}$ ) is higher than PIL-C6 (peak maximum = $321 \mathrm{~K}$ ).

\section{Rheometric data measurements}

The viscosity of PILs was measured by a TA instruments AR-G2 rheometer using $25 \mathrm{~mm}$ parallel aluminum plates at $23{ }^{\circ} \mathrm{C}$ in air at $1 / \mathrm{s}$ shear rate. Table S1 shows the viscosity of PILs.

Table S1. Experimental results for the viscosity of PILs at $23{ }^{\circ} \mathrm{C}$ and $1 / \mathrm{s}$ shear rate. The viscosity of PIL-C6 was not be obtained due to crystallization.

\begin{tabular}{cc}
\hline PIL & $\begin{array}{c}\text { Viscosity at } 23{ }^{\circ} \mathrm{C} \\
(\mathrm{Pa} \cdot \mathrm{s})\end{array}$ \\
\hline PIL-C6 & - \\
PIL-C8 & 50.5 \\
PIL-C12 & 241.9 \\
PIL-C16 & 283.7 \\
\hline
\end{tabular}

\section{Preparation of PIL shockwave impact test specimens}

The specimen configuration for shockwave testing is shown schematically in the main manuscript in Figure 3a. The two glass substrates were cleaned with piranha solution (a mixture of sulfuric acid and hydrogen peroxide). The energy absorbing layer was prepared by depositing a $400 \mathrm{~nm}$ aluminum layer on the glass 
substrate by electron beam deposition, and a $200 \mathrm{~nm}$ aluminum layer was deposited on the other glass substrate for reflection. A sodium silicate solution was spin coated on the $400 \mathrm{~nm}$ aluminum layer to provide a $6 \mu \mathrm{m}$ thick transparent water glass confining layer. PIL-C8,-C12, and -C16 test specimens were prepared by drop casting $25 \mathrm{mg}$ of each PIL on the glass substrate and sandwiching between the two glass substrates with a $50 \mu \mathrm{m}$ thick polyimide spacer to maintain uniform thickness of PIL layer. Gentle pressure was applied on both glass substrates using binder clips at least for 30 minutes before laser-induced shockwave test. In a similar manner, melted PIL-C6 was drop cast on the glass substrate and sandwiched between the two glass substrates with a $50 \mu \mathrm{m}$ thick polyimide spacer. The amorphous PIL-C6 sample was tested by the laser-induced shockwave test setup within an hour of preparation, and the crystalline PIL-C6 was tested after 24 hours of sample preparation, which offers enough time for crystallization.

\section{Laser-induced shockwave test protocols for the calculation of the peak pressure and the energy transferred.}

Details on laser-induced shockwave test protocols were introduced in the prior work. ${ }^{[2]}$ Our-of-plane displacement and velocity of the specimen surface were measured using a Michelson interferometer with a $532 \mathrm{~nm}$ diagnostic beam. A representative voltage trace is shown in Figure S2a, which is converted to displacement (Figure S2b) and free surface velocity (Figure S2c) as previously described by Wang and Gupta et al. ${ }^{[3-4]}$. Based on conservation of momentum and energy, the pressure profile, $P(t)$,

$$
P(t)=\rho_{0}\left(U_{s}(t)\right) U_{p}(t)=\rho_{0}\left(s+c U_{p}(t)\right) U_{p}(t),
$$

and the energy transferred profile, $J(t)$, (as previously described by Forbes), ${ }^{[5]}$

$$
J(t)=\frac{1}{2} \rho_{0} \int_{0}^{t}\left(U_{p}(t)\right)^{2}\left(s+c U_{p}(t)\right) d t,
$$

were calculated from the velocity profile, where $\rho_{0}$ is the initial material density and $U_{p}(t)$ is the particle velocity (Figure S2d,e). $U_{s}-U_{p}$ Hugoniot relation of the substrate was used to obtain $s$ and $c$, which are fitted parameters. Figure S3 shows energy transferred per area at different input laser fluences for PILs. 
(a)

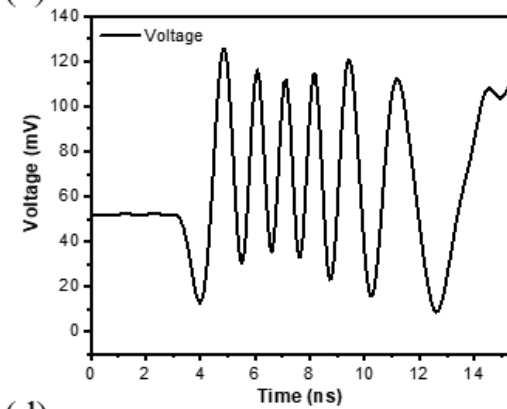

(d)

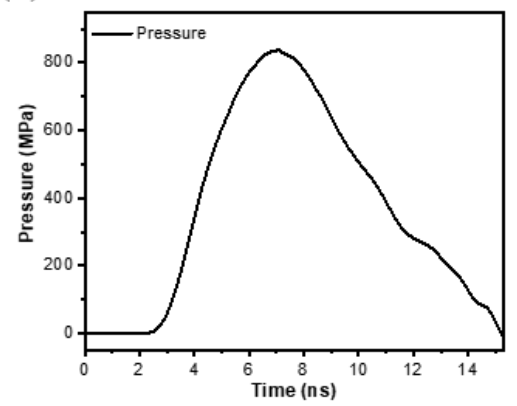

(b)

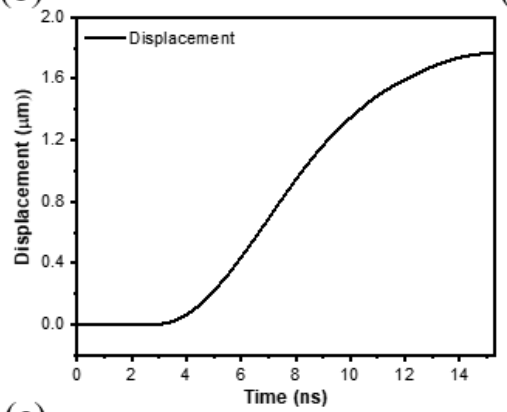

(e)

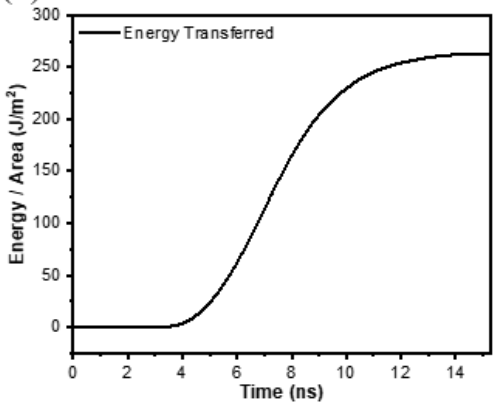

(c)

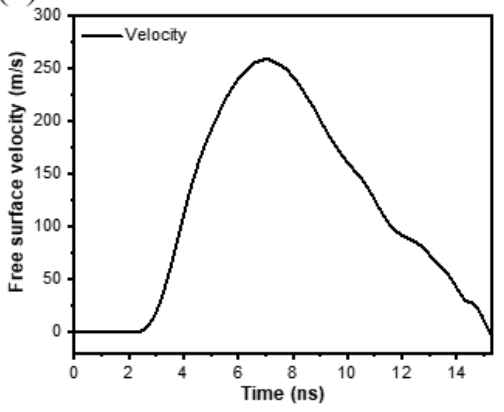

Figure S2. Representative data obtained from the laser-induced shockwave test for amorphous PIL-C6 at $84.3 \mathrm{~mJ} / \mathrm{mm}^{2}$ input laser fluence: (a) interferometrically measured voltage data, (b) displacement profile calculated from the voltage trace as described previously by Wang and Gupta et al., [3,4] (c) free surface velocity as the $1^{\text {st }}$ derivative of the displacement, (d) pressure profile calculated from Eq. (1), and (e) energy transferred per area calculated from Eq. (2). Details on test protocols were described in the prior work. [2]

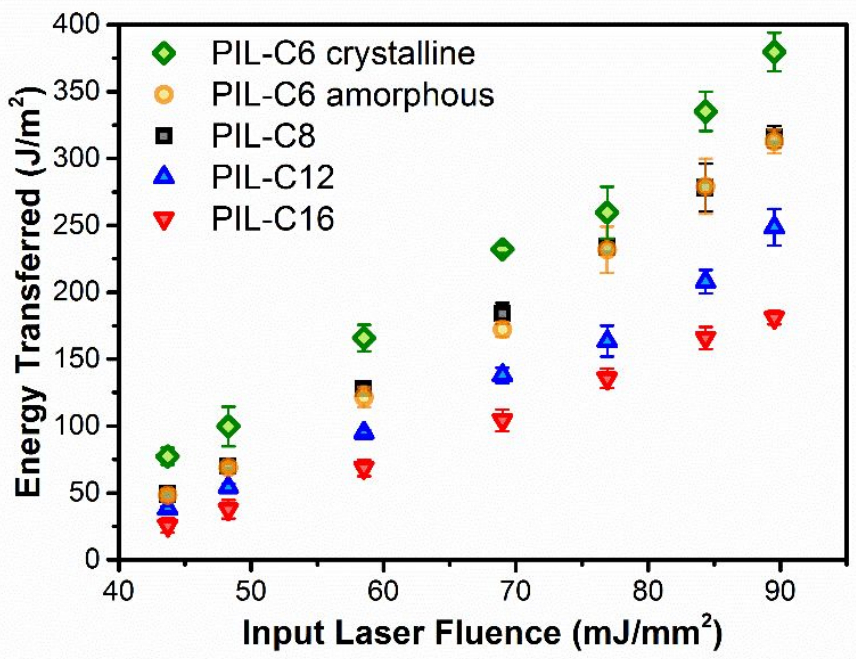

Figure S3. Energy transferred per area at different input laser fluences for PILs. 


\section{References}

(1) Sebastian, L.; Rainer, S., Total Synthesis and Absolute Configuration of Epicoccamide D, a Naturally Occurring Mannosylated 3-Acyltetramic Acid. Chemistry - A European Journal 2013, 19, 10619-10624.

(2) Yang, K.; Lee, J.; Sottos, N. R.; Moore, J. S., Shock-Induced Ordering in a NanoSegregated Network-Forming Ionic Liquid. Journal of the American Chemical Society 2015, $137,16000-16003$.

(3) Wang, J.; Weaver, R. L.; Sottos, N. R., A Parametric Study of Laser Induced Thin Film Spallation. Experimental Mechanics 2002, 42, 74-83.

(4) Gupta, V.; Argon, A. S.; Parks, D. M.; Cornie, J. A., Measurement of Interface Strength by a Laser Spallation Technique. Journal of the Mechanics and Physics of Solids 1992, 40, 141-180.

(5) Forbes, J. W., Shock Wave Compression of Condensed Matter. Springer-Verlag Berlin Heidelberg: 2012. 
